УДК 681.2

\title{
ЕФЕКТИВНІСТЬ ВИКОРИСТАННЯ ШТУЧНИХ НЕЙРОННИХ МЕРЕЖ В ЕКОНОМІЦІ
}

\section{EFFICIENCY OF USING ARTIFICIAL NEURAL NETWORKS IN THE ECONOMY}

\author{
Бурлєєв Олег Леонідович \\ кандидат технічних наук, доцент, \\ Український гуманітарний інститут \\ ORCID: https://orcid.org/0000-0002-6450-8618 \\ Василенко Олег Олегович \\ аспірант спеціальності комп'ютерна інженерія, \\ Інститут кібернетики Національної академії наук України \\ ORCID: https://orcid.org/0000-0001-8498-2950 \\ Іваненко Ростислав Михайлович \\ студент, \\ Український гуманітарний інститут \\ ORCID: https://orcid.org/0000-0001-5434-5344 \\ Burlieiev Oleh \\ Institute of Arts and Sciences \\ Vasylenko Oleh \\ National Academy of Sciences of Ukraine \\ Ivanenko Rostyslav \\ Institute of Arts and Sciences
}

В статті досліджено особливості створення штучних нейронних мереж, їх навчання, застосування в економічній сорері та порівняння їх ефективності з статистичними методами. Встановлено, що наукові роботи стосовно нейронних мереж є лише загальними та не відображають особливості використання різних архітектур. Проведене дослідження особливостей різних ядер нейромереж на основі методу опорних векторів та порівняння їх ефрективності між собою для класифікації даних. Завдяки дослідженню показано, що метод опорних векторів дозволяє нам ефективно класифрікувати дані, в тому числі з нелінійною структурою. 3'ясовано, що нейронні мережі дійсно ефективні для аналізу економічних показників і вже значно випереджають класичні методи аналізу. Встановлено, що нейромережі використовуються для вирішення трьох основних типів задач: прогнозування, класифікація та моделювання. Представлено платформи та бібліотеки, що допомагають при створенні нейронної мережі та мають готові зразки використання та детальну документацію. Підтверджено, що основні переваги нейронних мереж - це здатність до навчання, можливість працювати 3 неповними даними, можливість автоматизувати аналіз, висока точність результатів. 3'ясовано, що основні недоліки нейромереж - це технічні вимоги, необхідність великої кількості зібраних і оброблених даних для навчання та складність реалізації в кожному окремому випадку. Представлено найбільш поширені типи нейромереж та алгоритми навчання, а також в задачах яких типів будуть ефективними різні нейронні мережі. Запропоновано порівняння ефективності перцептрона та логістичної регресії при вирішенні однакової задачі класифрікації. Отже, штучні нейронні мережі дійсно переважають класичні методи аналізу даних, а розмір цієї переваги буде залежати від кількості фракторів, що впливають на результат та складності взаємозв'язків між ними.

Ключові слова: штучні нейронні мережі, застосування нейронних мереж, економіка, ефективність, порівняння з класичними методами аналізу даних.

В статье исследованы особенности создания искусственных нейронных сетей, их обучения, применение в экономической сфере и сравнение их эффективности со статистическими методами. Установлено, что научные работы по нейронным сетям - лишь общие и не отражают особенности использования различных архитектур. Проведено исследование особенностей различных ядер нейросетей на основе метода опорных 
векторов и сравнение их эффрективности между собой для классификации данных. Исследование показало, что метод опорных векторов позволяет нам эффрективно классифицировать данные, в том числе с нелинейной структурой. Выяснено, что нейронные сети действительно эффрективны для анализа экономических показателей и уже значительно опережают классические методы анализа. Установлено, что нейросети используются для решения трех основных типов задач: прогнозирование, классификация и моделирование. Представлены платфрормы и библиотеки, помогают при создании нейронной сети и имеют готовые образцы использования и подробную документацию. Подтверждено, что основные преимущества нейронных сетей это способность к обучению, возможность работать с неполными данными, возможность автоматизировать анализ, высокая точность результатов. Выяснено, что основные недостатки нейронных сетей - это технические требования, необходимость большого количества собранных и обработанных данных для обучения и сложность реализации в каждом отдельном случае. Представлены наиболее распространенные типы нейронных сетей и алгоритмы обучения, а также в каких типах задач различные нейронные сети будут особенно эффрективными. Представлено сравнение эфффективности перцептрона и логистической регрессии при решении одинаковой задачи классификации. В итоге, искусственные нейронные сети действительно обладают преимуществами по сравнению с классическими методами анализа данных, а величина этих преимуществ зависит от ряда фракторов, влияющих на результат, и сложности взаимосвязей между данными.

Ключевые слова: искусственные нейронные сети, применение нейронных сетей, экономика, эфрективность, сравнение с классическими методами анализа данных.

Much research has been devoted to neural networks, however there is little information available on effectiveness of different architectures in economics. The article investigates the peculiarities of artificial neural networks creation, their training, application in economics, and compares their effectiveness by statistical methods. A comparative study of the features of neural network kernels based on the support vector machine method with other methods for data classification shows that the support vector machine method is effective data classification tasks, especially for data with non-linear structure. Therefore, neural networks are really effective for the analysis of economic indicators and already far ahead of classical methods of analysis. Neural networks are used to solve three main types of tasks: forecasting, classification and modeling. Presented in the article are platforms and libraries, that help in creating a neural network and have ready-to-use samples and detailed documentation. The main advantages of neural networks are the ability to learn, the ability to work with incomplete data, the ability to automate the analysis, the high accuracy of the results. The main disadvantages of neural networks are the technical requirements, the need for a large amount of collected and processed data for training and the complexity of implementation in each individual case. The most common types of neural networks and training algorithms are presented, as well as economical tasks that are solved effectively by different types of neural networks. Performance of neural network perceptron and logistic regression were tested on the same data. These approaches have offered generally similar level of accuracy when solving the same test classification problem, with perceptron showing 3,5\% more accurate result. In conclusion it can be said that artificial neural networks may offer more accurate result compared to classical methods of data analysis. Accuracy depends on type of task, amount and type of available data, and the complexity of the relationship between data.

Keywords: artificial neural networks, application of neural networks, economics, efficiency, comparison with classical methods of data analysis, SVM, support vector machine.

Постановка проблеми. Зміни в економічних процесах і показниках мають значний вплив на кожну конкретну людину і людство в цілому. Якщо проаналізувати діяльність будьякої людини, то ми помітимо, що питання економічного характеру будуть займати в їі житті провідні місця. Тому, надзвичайно важливо аналізувати економічні процеси швидко і витрачати при цьому мінімум інтелектуальних ресурсів та зменшувати рівень похибки. 3 розвитком інформаційних наук та спостереженням за будовою нашого мозку виникли нейронні мережі, які здатні значно пришвидшити аналіз даних і зменшити похибку. А також знаходити в процесах чи явищах, що аналізуються, нелінійні залежності, закономірності та причинно-наслідкові зв'язки, які при вузькому розгляді даних можуть бути не враховані. Найбільш ефективними нейронні мережі показують себе при роботі з великою кількістю даних, які людина фрізично не здатна сприйняти. До прикладу, сьогодні кожен користується пошуковими сервісами, електронними платіжними системами та смартфонами 3 геолокацією, тому штучні нейронні мережі широко використовуються корпораціями для того, щоб знайти, який товар зацікавить кожного конкретного покупця, або для персоналізованої реклами, на основі даних отриманих про користувача (при умові наявності цих даних). Проте можна сказати, що нейронні мережі не $є$ досконалим інструментом і мають ряд недоліків, оскільки існує багато архітектур, що розраховані для вирішення окремих завдань та потребують тривалого процесу навчання і значної кількості даних. Але при правильному виборі типу мережі і їі подальшому налаштуванні та навчанні можна досягнути виняткових результатів в аналізі великої кількості даних. Саме тому, дослідження теми 
застосування нейронних мереж в економіці $\epsilon$ актуальним та необхідним науковим напрямом, який потребує глибшого дослідження.

Аналіз останніх досліджень і публікацій. Дослідженням засобів використання нейронних мереж в економіці займалося чимало науковців. До прикладу кандидат економічних наук Новікова В.В. зазначила, що: «Необхідно використовувати прогнозування ВВП для оцінки найважливіших макроекономічних параметрів, яке можливо здійснювати за допомогою побудови моделі нейронної мережі, що дозволить отримувати найбільш ефективні прогнози в майбутньому» [1, с. 5-7]. Більше того науковці 3 Ярославського державного університету ім. П.Г. Демидова вважають, що фрінансове прогнозування сьогодні $€$ найбільш поширеною сорерою використання моделей нейронних мереж в вітчизняній економіці [2, с. 52-60]. Аспірант Каргин Б.Б. зауважує, що в наш час традиційні підходи до вирішення інформаційних задач значно поступаються абсолютно новим напрямкам, таким як нейронні мережі [3, с. 235-240]. Кандидат технічних наук, доцент Максимова О.М. додає, що: «Нейронні мережі - виключно потужний метод моделювання, що дозволяє відтворювати надзвичайно складні залежності» [4, с. 2-3]. Крім того, магістр Науменко В.А. вважає, що: «Найбільш продуктивними сорерами застосування нейронних мереж будуть ті, в яких людський інтелект малоефективний і аналітичні обчислення трудомісткі та фрізично нераціональні» [5, с. 1-12]. Проте кандидат педагогічних наук, доцент Григорьева Д.Р. в своїй праці висловлює думку, що основними конкурентами для нейронних мереж залишаються класичні методи аналізу даних [6, с. 3-4]. Однак серед проаналізованих праць виявлено відсутність кількісного порівняння ефрективності нейронних мереж 3 класичними методами аналізу даних. Тому основною метою роботи визначено встановлення рівня ефрективності використання нейронних мереж в економіці у порівнянні з класичними методами аналізу даних.

Виклад основного матеріалу дослідження. У дослідницьких працях широко висвітлено переваги нейронних мереж над традиційними методами аналізу фрінансових показників, таких як дискримінантний аналіз і логістична регресія. Нейронні мережі гнучкі і фрункціональні, що дозволяє їм узагальнювати будь-яку непереривну і нелінійну фрункцію. Таким чином з'являється можливість представляти ефрективні нелінійні моделі для фрінансових ринків і прогнозувати зміни точніше. Проте в дослідницьких працях науковців виявлено, що в деяких задачах традиційні методи аналізу і нейронні мережі показують однакову точність. Встановлено, що основною проблемою використання нейронних мереж в економіці $є$ обрання відповідного розміру мережі (кількості шарів або нейронів). I тому реалізація мережі спирається на метод проб і помилок. Хоча раніше намагалися систематизувати методологію та все ще немає відповідного всеохоплюючого дослідження. Можемо зазначити, що нейронні мережі ефрективніші за традиційні методи аналізу, оскільки мають більшу гнучкість і точність, але мають і певні недоліки, такі як необхідність об'ємних розмічених даних для навчання, час та значні обчислювальні потужності.

Отже, проаналізувавши вислови та думки науковців констатуємо, що роботи стосовно нейронних мереж $є$ лише загальними та не відображають особливості використання різних архітектур.

Процес створення штучної нейронної мережі поділяють на чотири основні етапи: підготовка даних, створення алгоритму, навчання алгоритму на підготовлених даних, перевірка алгоритму на тестових даних. У випадку, коли всі етапи успішно пройдені, її можна застосовувати на практиці і зі значною ймовірністю отримати вірний результат.

Для початку, взагалі будь-яке навчання поділяють на два типи - індуктивне та дедуктивне навчання. Індуктивне полягає в спостереженні за певним явищем і побудові певної моделі, яка потім перевіряється на практиці, і якщо вона виявляється вірною, то використовується надалі, якщо ні, то видаляється. Дедуктивне навчання полягає в використанні на практиці вже готових правил і фрормул. Навчання нейронних мереж відносять до індуктивного. По своїй суті нейронна мережа - це фрункція 3 великою кількістю параметрів, яка отримує на вхід певний вектор значень і потім десрормує його в просторі за допомогою коефріцієнтів, які сфрормувались в процесі навчання. $€$ два основі підходи до навчання нейромереж - це навчання з вчителем і навчання без вчителя. Існує велика кількість і різноманітність алгоритмів навчання нейронних мереж, найбільш поширені 3 них: навчання з зворотним поширенням помилки, навчання 3 радіальними базисними фрункціями і навчання опорних векторів. Навчання з зворотним поширенням помилки полягає в тому, щоб після кожної ітерації визначалось загальне відхилення від очікуваного результату, а потім корегувався (посилювався чи 
послаблювався) вклад кожного зв'язку між нейронами, щоб з кожним циклом навчання, наближатися до правильного набору коефріцієнтів. Також, важливо в процесі навчання нейронної мережі уникнути перенавчання, для цього потрібно щоб мережа вчилась на дійсно великій кількості прикладів та знаходила загальні, а не часткові закономірності.

Будь-яка мова програмування дозволяє працювати 3 нейронними мережами, однак мова Python найбільш пристосована для цього і має велику кількість вбудованих інструментів. Створено велику кількість платорорм і бібліотек, які дозволяють пришвидшити розробку власних нейромереж. Зокрема, платфорома Jupyter, яка $€$ безкоштовним проектом 3 відкритим кодом та стандартами, який надає послуги для інтерактивних обчислень на багатьох мовах програмування, в тому числі послуги перетворення даних, статистичного моделювання, візуалізації даних та машинного навчання. Платорорма TensorFlow має відкритий код та велику кількість вже готових інструментів та бібліотек для машинного навчання. Бібліотеки, що широко використовуються для навчання - Theano, Keras, SciKit-Learn, Pandas, NumPy, CUDA. Theano бібліотека, що оптимізує обчислення великих математичних виразів, особливо у вигляді матриць. Keras - бібліотека, яка може працювати поверх інших бібліотек для прискорення експериментів 3 штучними нейронними мережами, містить в собі велику кількість інструментів для роботи 3 текстом та зображеннями. SciKit-Learn (sklearn) - одна з найбільш популярних бібліотек, працює разом з SciPy та NumPy, надає можливості для створення і тренування алгоритмів машинного навчання (регресії, кластеризації та класифрікації) . Pandas - бібліотека, що дозволяє працювати з чисельними рядами та рядами динаміки, а також зручніше маніпулювати даними. NumPy - бібліотека, що надає мові програмування Python можливість працювати з великими багатовимірними масивами та матрицями. CUDA - набір бібліотек, створений Nvidia, який дозволяє швидко та ефективно використовувати обчислювальні потужності графрічного процесора. Також існує велика кількість прикладних програм для використання нейронних мереж: Matlab, STATISTICA Neural Networks, Brain Maker Pro, Excel Neural Package. Значна частина прикладних програм є комерційними продуктами.

Для задач аналізу та класифрікації широко застосовується метод опорних векторів
(SVM). SVM - це метод аналізу, який використовується для побудови моделі, яка б відносила дані до однієї з двох груп, при цьому дані зображуються як точки у просторі, які розділені певною лінією. Потім нові дані наносяться на той самий простір і робиться припущення про їх належність до певної групи в залежності від того, на який бік лінії вони потрапили . На основі SVM створено наступні найпоширеніші ядра нейромереж: Linear, RBF, Polynomial kernels та інші. Кожне ядро показує свою максимальну ефективність в певних задачах, наприклад Linear i Polynomial в завданнях лінійної класифікації, RBF в нелінійних. На рисунку 1 можна побачити різницю між математичними підходами різних ядер для побудови моделі, яка відносить результат до певної групи (задача класифрікації). Дані було візуалізовано за допомогою платорорми Jupyter і бібліотеки sklearn.

Навіть візуально можна побачити, що модель класифрікації 3 використанням RBF ядра, краще підходить для обраних даних 3 нелінійною структурою. Це підтверджується і перевіркою моделі на тестових даних 3 допомогою метрики Accuracy: точність моделі 3 RBF ядром становить 98\%, точність моделі 3 Linear ядром становить 76\%, точність моделі 3 Polynomial ядром становить $77 \%$.

Отже, метод опорних векторів дозволяє нам ефрективно класифрікувати дані, в тому числі 3 нелінійною структурою. А можливість побудови нелінійних моделей дозволяє краще класифрікувати дані, що змінюються за нелінійними законами, а вони складають невід'ємну частину нашого життя.

Типів нейронних мереж достатньо велика кількість і кожен з них має свої особливості. Але у всіх з них $є$ характерна особливість, яка надає їм ряд переваг перед традиційними статистичними методами і алгоритмами, це можливість навчання. Суть навчання полягає в пошукі коесріцієнтів для зв'язків між нейронами, які б відображали всі залежності між вхідними даними і очікуваним результатом та потім в узагальненні результатів. Після успішного навчання, узагальнення надає можливість отримувати вірний результат навіть при умові десормованих чи деяких відсутніх значень. Серед основних загальних сорер застосування нейронних мереж можна виділити такі, як прогнозування, класисрікація і моделювання.

Серед найбільш поширених і корисних в практичному застосуванні нейронних мереж $\epsilon:$ багатошаровий перцептрон, згорткова нейронна мережа і мережа радіально-базис- 


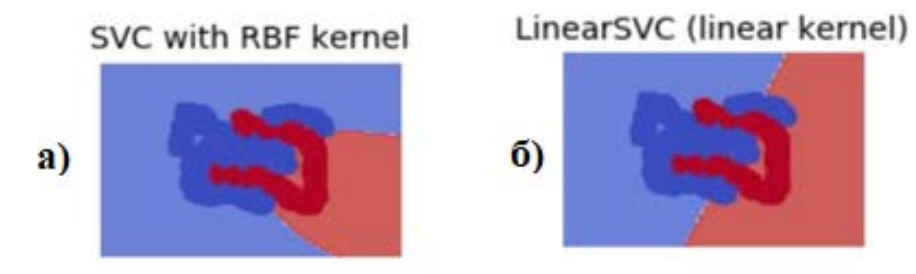

SVC with polynomial kernel

B)

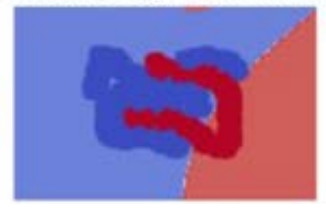

Рис. 1. Візуалізація розподілу даних

3 використанням різних ядер нейромереж:

а) ядро радіально базисних фрункцій;

б) лінійне ядро; в) поліноміальне ядро

них фрункцій. Перцептрон - одна 3 перших моделей нейромереж, але не дивлячись на свою простоту він здатний вирішувати складні завдання, складається 3 декількох шарів, які можуть варіюватися. В економічній сорері він найбільш ефективно працює з задачами прогнозування, класисрікації, регресії. Згорткова нейронна мережа має однонаправлену структуру і деяку кількість шарів нейронів. Це один 3 кращих алгоритмів для класифікації, має зручне розпаралелювання підрахунків, що дозволяє значно прискорити роботу мережі 3 допомогою графрічних процесорів. Мережа радіально-базисних фрункцій складається 3 вхідного шару, радіальних елементів, прихованого шару та лінійного вихідного шару. Широко застосовується, зокрема, для класифрікації, побудови фрункції наближення (апроксимації), прогнозування рядів динаміки (часових рядів). Головною проблемою, яку слід вирішувати при навчанні нейронної мережі $€$ пошук глобального мінімуму помилки і уникнення застрявання в локальному мінімумі. Одним 3 варіантів вирішення цієї проблеми є застосування методу градієнтного спуску та правильно підібраного розміру кроку або його адаптивності.

Отже, рівень ефрективності і точності нейронної мережі напряму залежить від ії типу, структури, розміру навчальної вибірки і того, наскільки точно буде визначений глобальний мінімум помилки. Різні задачі потребують різних типів нейромереж.

Штучні нейронні мережі вже сьогодні довели свою ефрективність при розв'язанні багатьох реальних економічних задач пов'язаних з ринком і банківською сорерою: бізнес-аналітиці, оцінці ризиків, оцінці платіжної спроможності банківських клієнтів, оцінці вартості нерухомості, прогнозуванні рівня попиту на нову послугу чи товар, прогнозуванні об'ємів продажів, прогнозуванні ціни акцій, прогнозуванні біржових курсів тощо. Точність їх прогнозів і оцінок залишається на високому рівні, але вони не можуть досягти дійсно вражаючих результатів 3 точністю наближеною до 100\%. Саме через значну кількість чинників, реальний вплив яких змінюється та даним 3 якими вони працюють, які іноді не повністю висвітлюють реальні процеси і різноманітні тіньові фрактори. Проте деяку неточність даних можна нівелювати за рахунок збільшення кількості цих даних.

Завдяки сучасним цифрровим технологіям та всесвітній мережі інтернет кількість доступних даних і їх якість зросла в десятки разів. Їх використання 3 допомогою нейронних мереж вже сьогодні підвищує ефективність реклами та сприяє комсоорту споживачів. Але не дивлячись на вражаючі результати штучних нейронних мереж іноді їх використання недоцільне і буде цілком достатньо статистичних засобів для аналізу даних, які в окремих задачах не поступаються нейронним мережам. Наприклад, при спробі розв'язати з допомогою статистичних методів (логістичної регресії) та нейронних мереж (багатошарового перцептрону) однакову задачу класифрікації рівня активності клієнта банку на основі анонімізованих даних про клієнтів цього банку, було отримано результати, що представлені на рисунках 3 та 4.

При вирішенні цієї задачі був використаний перцептрон з двома внутрішніми шарами наступної структури (рис. 2).

Аналіз був проведений на платфрормі SAS Viуa. В результаті 1060038 спостережень було 

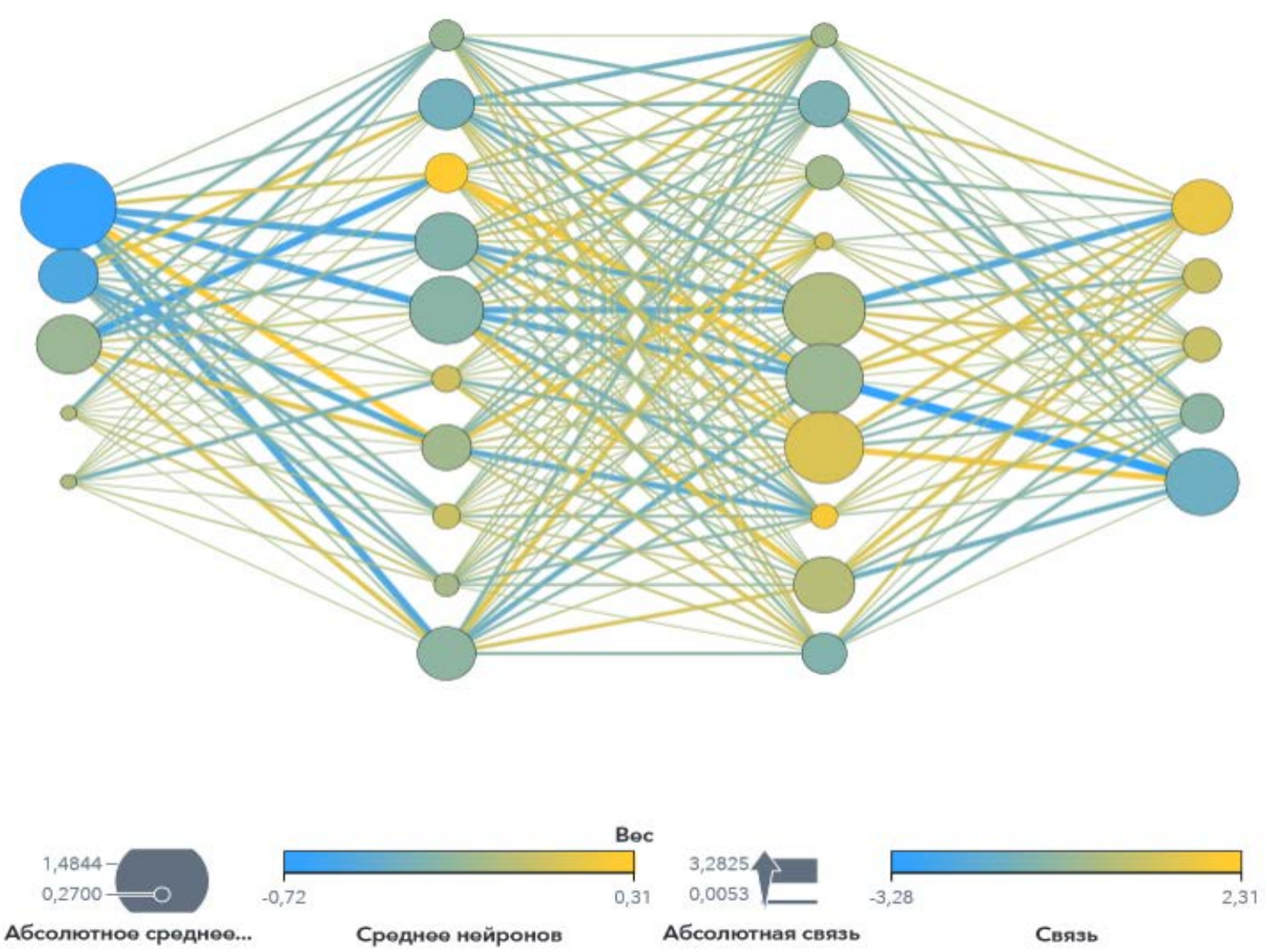

Рис. 2. Структура використаного перцептрона

отримано наступні показники: точність роботи штучної нейронної мережі склала 93,21\%. Точність класифрікації 3 використанням логістичної регресії, при використанні однакових вхідних даних, склала 89,68\%. Тобто, різниця в точності склала приблизно 3,5\%.

Якщо порівнювати між собою статистичні методи аналізу та нейронні мережі, то можна виділити їх наступні переваги та недоліки.
Статистичні методи простіші в використанні, не потребують значних об'ємів даних і обчислювальних потужностей та часу для навчання, однак їх точність і можливість швидко працювати 3 великими об'ємами інфрормації дещо менша. Штучні нейронні мережі мають ширші можливості при автоматизації аналізу даних та показують більшу точність результатів при використанні готової мережі, проте потре-

\section{Помилкова класифікація}

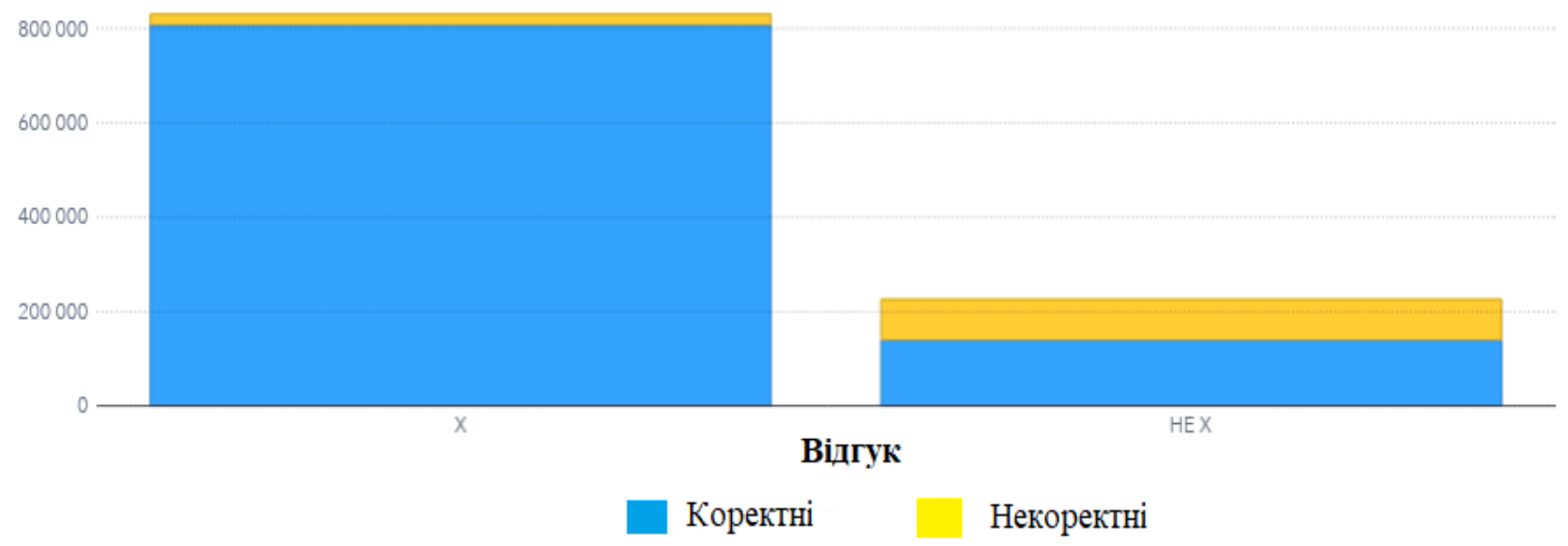

Рис. 3. Точність класифрікації з допомогою логістичної регресії 


\section{Помилкова класифікація}

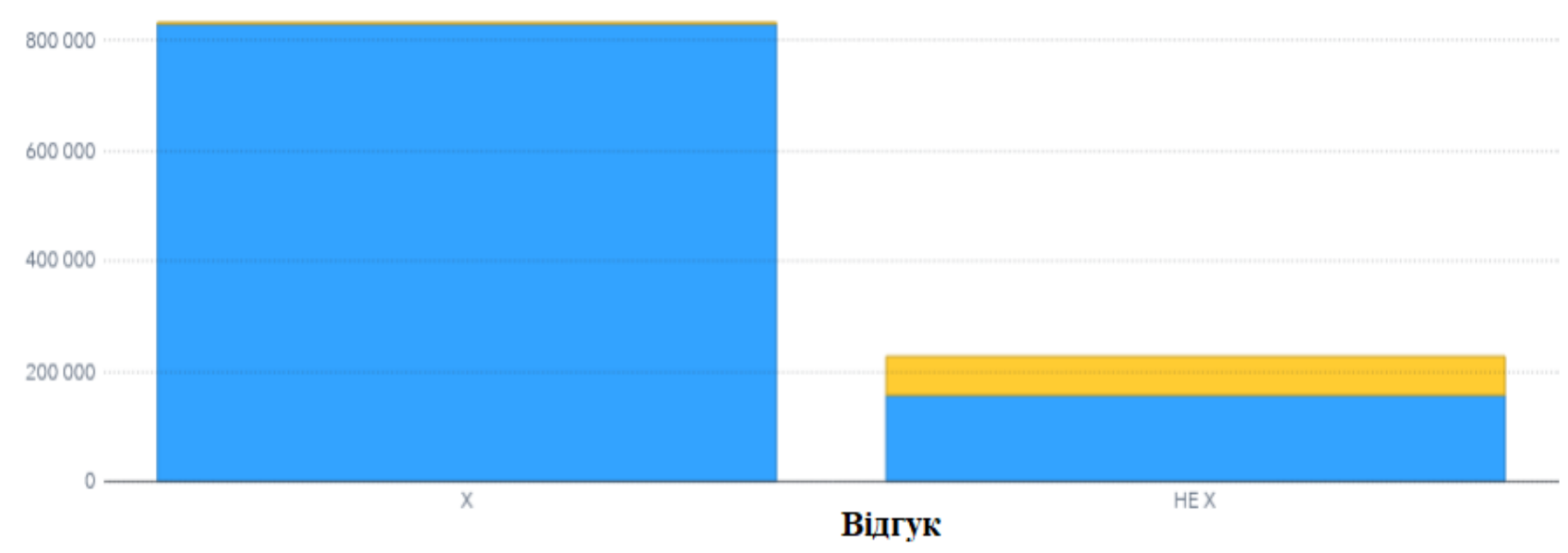

Коректні Некоректні

Рис. 4. Точність класифрікації з допомогою багатошарового перцептрону

бують значних зусиль та часу при створенні і навчанні мережі або значних коштів при використанні вже готових рішень. Навіть при умові, що статистичні методи поступаються нейромережам в ефрективності, вони потребують значно менших матеріальних і інтелектуальних вкладень та витрат тому, їх практична корисність іноді може бути вищою. Тому потрібно економічно обґрунтовувати доцільність впровадження і розроблення нейромережі для вирішення будь-якої прикладної задачі щоб визначити чи буде вартувати отримане покращення затрачених ресурсів. Чи буде цілком достатньо доступніших статистичних методів аналізу.

Отже, підсумуємо основні результати дослідження, які полягають в наступному. Створення нейромережі це трудомісткий процес, який потребує глибокого розуміння задачі, для вирішення якої створюється мережа та специорічних відмінностей між різними структурами мереж, типами навчання та ядрами нейромереж, а також потребує значної кількості даних та обчислювальних потужностей. Існує значна різноманітність бібліотек та платформ, які мають детальну документацію та значно спрощують підготовку даних, роботу 3 великими об'ємами інформації, пришвидшують навчання, дозволяють ефективніше використовувати обчислювальні потужності пристроїв, надають вже готовий інструментарій. Нейронні мережі дійсно переважають класичні методи аналізу даних, однак розмір цієї переваги буде відрізнятися в залежності від кількості фракторів, що впливають на досліджуване явище та складності взаємозв'язків цих фракторів. Іноді ця перевага буде не значною, тому цілком можливо надати перевагу класичним методам аналізу завдяки їх доступності.

Висновки. Підводячи підсумки по даному дослідженню, а саме ефрективності використання штучних нейронних мереж в економіці зазначимо, що це питання виявилось достатньо актуальним на сьогодні завдяки активному розвитку інфрормаційних технологій та необхідності швидкої обробки великих об'ємів інформації. Більшість науковців погоджуються 3 перевагою нейромереж над традиційними методами аналізу даних, проте приблизний розмір цієї переваги не зазначається, хоча він звичайно буде відрізнятися в кожному окремому випадку. Теоретичні дослідження підтвердили, що нейронні мережі дійсно ефективні для аналізу економічних показників i вже значно випереджають класичні методи аналізу. Встановлено, що нейромережі використовуються для вирішення трьох основних типів задач: прогнозування, класифрікація та моделювання. Було визначено, що основні переваги нейронних мереж - це здатність до навчання, можливість працювати з неповними даними, можливість автоматизувати аналіз, висока точність результатів. Однак, технічні вимоги, необхідність великої кількості зібраних даних для навчання та складність реалізації в кожному окремому випадку не дозволяють назвати нейронні мережі універсальними для всіх завдань. В той же час практичні дослідження майже повністю корелюються із результатами теоретичного аналізу наукової літератури, а саме при розв'язанні однакової 
задачі перцептрон виявився на 3,5\% точніший за логістичну регресію. Також можемо зазначити, що розмір переваги буде змінюватися в залежності від кількості фракторів та складності взаємозв'язків між ними. Тому варто зауважити, що проведене дослідження буде корисним для маркетингових відділів підприємств, а також для банківських і державних установ та допоможе їм оглянути всі переваги та недоліки нейронних мереж у порівнянні 3 класичними методами аналізу даних. I допоможе їм прийняти рішення чи буде вартувати використання аналізу з допомогою штучних нейронних мереж затрачених ресурсів.

\section{СПИСОК ВИКОРИСТАНИХ ДЖЕРЕЛ:}

1. Новікова В.В. Прогнозування внутрішнього валового продукту на основі апарату штучних нейронних мереж. Економіка та управління АПК. 2014. № 1. С. 5-11.

2. Курочкина И.П., Калинин И.И., Маматова Л.А., Шувалова Е.Б. Нейронные модели в диагностике финансового результата предприятий жилищно-коммунального хозяйства. Статистика и математические методы в экономике. 2019. № 3. С. 52-60.

3. Каргин Б.Б. Новые подходы к решению инсрормационных задач в экономике и коммерции. Theoretical and Practical Aspects of Economics and Intellectual Property. 2017. № 16. C. 235-240.

4. Максимова О.М., Стёпина Е.Н. Использование нейронных сетей для решения задач строительной механики. URL: https://core.ac.uk/download/pdf/38644194.pdf/ (дата звернення: 14.07.2021).

5. Науменко В.А. Применение нейронных сетей для решения практических задач в экономике. Вектор экономики. 2019. № 10. С. 1-12.

6. Григорьева Д.Р. Применение пакета statistica для анализа и прогнозирования экономических показателей предприятия. URL: https://kpfu.ru/portal/docs/F2101409340/Grigoreva.pdf (дата звернення: 10.08.2021).

\section{REFERENCES:}

1. Novikova V.V. (2014) Prohnozuvannia vnutrishnoho valovoho produktu na osnovi aparatu shtuchnykh neironnykh merezh [Prediction of gross domestic product based on the unit of piece neural fences]. Ekonomika ta upravlinnia APK, no. 1, pp. 5-11. (in Ukrainian)

2. Kurochkina I.P., Kalinin I.I., Mamatova L.A., Shuvalova E.B. (2019) Nejronnye modeli v diagnostike finansovogo rezul'tata predprijatij zhilishhno-kommunal'nogo hozjajstva [Neural models in the diagnosis of the financial result of housing and communal services enterprises]. Statistika i matematicheskie metody v jekonomike, no. 3, pp. 52-60. (in Russian)

3. Kargin B.B. (2017) Novye podhody k resheniju informacionnyh zadach $v$ jekonomike i kommercii [New approaches to solving information problems in economics and commerce]. Theoretical and Practical Aspects of Economics and Intellectual Property, no. 16, pp. 235-240. (in Russian)

4. Maksimova O.M., Stjopina E.N. Ispol'zovanie nejronnyh setej dlja reshenija zadach stroitel'noj mehaniki [Using neural networks to solve structural mechanics problems]. Retrieved from: https://core.ac.uk/download/ pdf/38644194.pdf/ (accessed 14 July 2021). (in Russian)

5. Naumenko V.A. (2019) Primenenie nejronnyh setej dlja reshenija prakticheskih zadach v jekonomike [Application of neural networks for solving practical problems in economics]. Vektor jekonomiki, no. 10, pp. 1-12. (in Russian)

6. Grigor'eva D.R. Primenenie paketa statistica dlja analiza i prognozirovanija jekonomicheskih pokazatelej predprijatija [Application of the statistica package for the analysis and forecasting of the economic indicators of the enterprise]. Retrieved from: https://kpfu.ru/portal/docs/F2101409340/Grigoreva.pdf (accessed 10 August 2021). (in Russian) 